\title{
Química de COORDENAÇÃO E BIologia: Controlo da Actividade Enzimática por AlteraçÃo da Coordenação de Centros Metálicos Catalíticos
}

\author{
Luisa B. Maia, Sofia R. Pauleta e José J. G. Moura* \\ REQUIMTE, Centro de Química Fina e Biotecnologia \\ Departamento de Química, Faculdade de Ciências e Tecnologia \\ Universidade Nova de Lisboa \\ jose.moura@fct.unl.pt
}

\begin{abstract}
Os
metais de transição, essenciais à vida, formam complexos muito estáveis com as cadeias laterais dos resíduos de aminoácidos que compõem as proteínas, definindo centros metálicos com geometrias definidas. Complexos com esferas de coordenação totalmente preenchidas não são propensos à interacção com substratos, pelo que, na maioria destes casos, é antecipada a função de transferência electrónica (centros de transferência electrónica). Contudo, em alguns casos, estes complexos constituem centros catalíticos inactivos. Complexos com esferas de coordenação incompletas, ou contendo grupos lábeis, podem formar centros catalíticos activos, que poderão coordenar substratos e activar reacções conducentes à formação de produtos. Desta forma, a actividade enzimática pode ser controlada por alterações da esfera de coordenação do centro metálico catalítico. A conversão de formas inactivas em formas activas pode ser despoletada pela alteração do número de coordenação, acompanhada por alterações conformacionais, criando posições de coordenação disponíveis para os substratos.
\end{abstract}

Serão discutidos exemplos que demonstram claramente que a esfera de coordenação do metal controla a actividade enzimática e, mais ainda, que mostram a dinâmica da transformação das espécies inactivas com consequentes rearranjos estruturais. Um tema comum será delineado onde ligandos e electrões controlam a actividade de metaloproteínas usando conceitos da Química de Coordenação.

\section{Abreviaturas}

ccNIR, nitrito redutase (penta-hémica)

CCP, peroxidase bacteriana (di-hémica)

$\mathrm{cd}_{1}$ NIR, nitrito redutase (contendo hemos $c$ e $d_{1}$ )

aminoácidos: asp, aspartato; cis, cisteína; gli, glicina; glu, glutamato; his, histidina; lis, lisina; met, metionina; tir, tirosina

\section{INTRODUÇÃO}

Os seres vivos desenvolveram mecanismos enzimáticos e percursos metabólicos para obterem energia e assimilarem moléculas de importância vital (assimilação e dissimilação) em resposta a variações ambientais. Muitas das soluções encontradas têm pontos comuns, reflectindo estratégias optimizadas conducentes à adaptação dos centros biológicos catalíticos para a captura de substratos. Neste artigo pretende-se ilustrar de que modo os metais que se encontram em centros catalíticos de metaloenzimas podem promover a activação e a inactivação pelo simples controlo/alteração da esfera de coordenação. O reconhecimento destes padrões de coordenação pode ser usado para prever a ocorrência de reacções biológicas.

A esfera de coordenação do metal controla a actividade enzimática [1]. Os enzimas são isolados em formas activas, capazes de interactuarem com os substratos e de acelerarem a formação de produtos diminuindo a energia de activação da reaç̧ão, ou em formas inactivas, que não reagem com os substratos e que por isso requerem etapas de activação. O processo de activação envolve muitas vezes mudança do estado de oxidação do metal, interaç̧ão com doadores/aceitadores de electrões e/ou com substratos, requerendo, em alguns casos, a presença de iões externos (e.g., cálcio). Muitos destes processos alteram o número de coordenação, que em alguns casos é acompanhada de alterações conformacionais, gerando formas activas a partir de formas inactivas. A remoção de ligandos da esfera de coordenação resulta numa diminuição do número de coordenação e promove a formação de posições livres para a coordenação de substratos (Figura 1). Do mesmo modo, a presença de ligandos muito fracos (e.g., uma molécula de água) pode facilitar a competição do substrato para a coordenação ao centro catalítico.

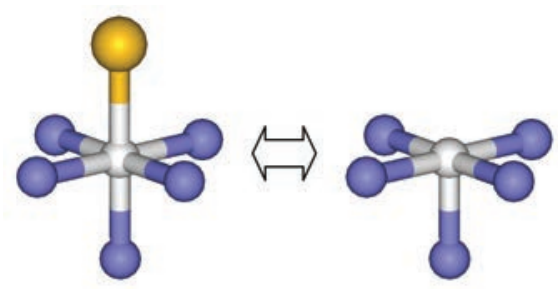

Figura 1 - Esquema de um centro metálico catalítico no estado inactivo e activo

O estado hexacoordenado representa um forma inactiva na reacção com um substrato (esfera de coordenação completa) e a forma pentacoordenada uma forma activa, com uma posição vaga de coordenação, com capacidade para ligar um substrato. A conversão activo/inactivo pode resultar de uma alteração de número de coordenação. 
Neste contexto, este artigo apresenta alguns exemplos de processos que ocorrem em proteínas hémicas e tem como objectivo exemplificar como as metaloproteínas controlam a actividade enzimática alterando as características do centro metálico onde ocorre a catálise. Os casos a discutir serão:

- uma proteína hémica isolada no estado activo, cujo centro activo apresenta uma esfera de coordenação não completamente preenchida - a nitrito redutase (ccNIR) de Desulfovibrio desulfuricans (ponto 4.1.);

- duas proteínas hémicas que requerem activação para atingir o estado activo - a nitrito redutase ( $\mathrm{cd}_{1} \mathrm{NIR}$ ) de Paracoccus denitrificans e a peroxidase bacteriana (CCP) de Marinobacter hydrocarbonoclasticus (pontos 4.2.).

Serão também descritos citocromos com esferas de coordenação completamente preenchidas, onde não pode ocorrer catálise e que estão optimizados para efectuarem transferência electrónica.

Muitos dos argumentos apresentados podem ser aplicados a outras situações, sendo estes conceitos gerais observados em metaloenzimas contendo centros de (i) ferro não hémico (e.g., superóxido redutases dependentes de ferro e hidrogenases dependentes de níquel e ferro); (ii) cobre (e.g., nitrito redutases dependentes de cobre e óxido nitroso redutase) e (iii) molibdénio/tungsténio (e.g., nitrato redutase e formato desidrogenase), entre outras.

Na parte final, será feita uma breve referência a alguns destes casos (várias referências são indicadas para os leitores interessados).

\section{Metais de transição, ligandos, esferas E NúmEROS DE COORDENAÇÃO}

Determinadas metaloproteínas têm como função a catálise de reacções biológicas e os metais de transição (oligoelementos) nelas contidos têm funções específicas. Metal e proteína desenvolveram uma interacção sinérgica, estabelecendo controlo estrutural das propriedades do metal pela estrutura proteica (relações estrutura/função). Alguns metais são activadores de enzimas, mas a maior relevância é em catálise, onde o centro metálico coordenado leva prioritariamente a cabo reacções redox (mas também reacções ácido-base).

A Tabela 1 lista, de modo não exaustivo, o papel dos metais na activação e catálise enzimática e no transporte de moléculas/iões, dando relevo ao vasto uso de metais de transição e à gama variada de reacções que são catalisadas.

Os centros catalíticos das metaloproteínas são formados por interacção directa de átomos coordenantes de cadeias laterais de aminoácidos, que formam ligações dativas com o metal. Em geral, os átomos coordenantes são de oxigénio, azoto e enxofre e os aminoácidos que são mais frequentemente encontrados em centros activos a coordenar metais de transição são o ácido glutâmico (glu), ácido aspártico (asp), tirosina (tir), histidina (his), lisina (lis), cisteína (cis) e metionina (met) (Figura 2, Tabela 2).

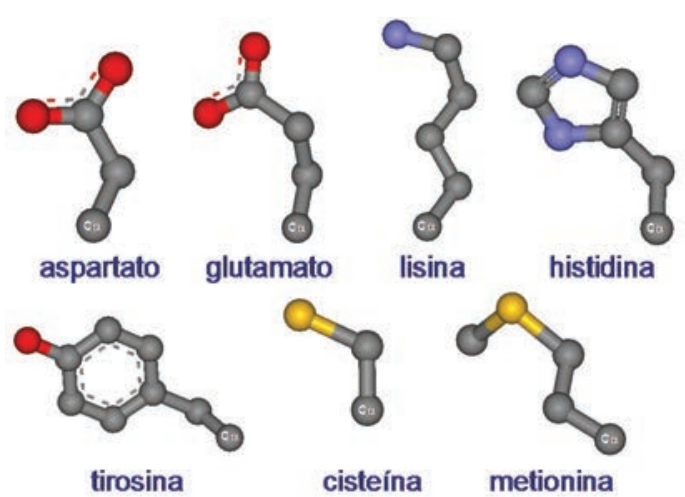

Figura 2 - Cadeias laterais de aminoácidos relevantes em coordenação de metaloproteínas

Representação da estrutura das cadeias laterais de aminoácidos e átomos coordenantes mais frequentemente envolvidos na interacção de proteínas com metais: aspartato, glutamato, histidina, tirosina, cisteína e metionina. A lisina, não frequentemente observada, é um ligando do hemo catalítico da ccNIR. Átomos coordenantes: oxigénio (vermelho), azoto (azul) e enxofre (amarelo). As imagens foram criadas com o programa Accelrys DS Visualizer v2.0 (Accelrys Software Inc.).

Tabela 2 - Iões metálicos em Biologia: ligandos preferidos e geometrias mais frequentes

\begin{tabular}{|c|c|}
\hline ião metálico & ligandos preferidos \\
\hline $\mathrm{Na}^{+}, \mathrm{K}^{+}$ & $\begin{array}{c}\text { ligandos oxigenados neutros ou com } \\
\text { carga }-1\end{array}$ \\
\hline $\mathrm{Mg}^{2+}, \mathrm{Mn}^{2+}$ & $\begin{array}{c}\text { carboxilatos, fosfato e dadores } \\
\text { azotados (porfirinas) }\end{array}$ \\
\hline $\mathrm{Ca}^{2+}$ & carboxilatos e fosfato \\
\hline $\mathrm{Fe}^{2+}$ & $\begin{array}{c}\text { grupos }-\mathrm{S}-\mathrm{e}>\mathrm{NH} \text { (imidazol, } \\
\text { porfirinas) }\end{array}$ \\
\hline $\mathrm{Fe}^{3+}, \mathrm{Co}^{3+}$ & $\begin{array}{c}\text { fenóis (tirosina), carboxilatos, } \\
\text { porfirinas }\end{array}$ \\
\hline $\mathrm{Cu}^{+}$ & $\begin{array}{c}\text { grupos }-S^{-} \text {(cisteína) e aminas } \\
\text { aromáticas }\end{array}$ \\
\hline $\mathrm{Cu}^{2+}$ & aminas, imidazol, grupos >N- \\
\hline $\mathrm{Zn}^{2+}$ & aminas, imidazol, grupos -S- \\
\hline $\mathrm{Ag}^{+}, \mathrm{Hg}^{2+}, \mathrm{Cd}^{2+}$ & grupos -S- e aminas \\
\hline $\mathrm{Pb}^{2+}$ & carboxilatos e grupos -S- \\
\hline ião metálico & geometrias mais frequentes \\
\hline $\mathrm{Cu}^{2+}$ & $\begin{array}{c}\text { tetragonal }>\text { coordenação } 5> \\
\text { tetraédrica }\end{array}$ \\
\hline $\mathrm{Ni}^{2+}$ & octaédrica > outras \\
\hline $\mathrm{Co}^{2+}$ & octaédrica > tetraédrica > outras \\
\hline $\mathrm{Zn}^{2+}$ & tetraédrica > octaédrica \\
\hline $\mathrm{Mn}^{2+}$ & octaédrica > outras \\
\hline $\mathrm{Fe}^{3+}$ & octaédrica > tetraédrica \\
\hline
\end{tabular}


Tabela 1 - Funções biológicas desempenhadas por iões metálicos

\begin{tabular}{|c|c|c|}
\hline proteína & reacção & função \\
\hline \multicolumn{3}{|c|}{ catálise enzimática / transporte de moléculas, iões } \\
\hline \multicolumn{3}{|c|}{ Ferro hémico } \\
\hline citocromo $c$ oxidase & redução do $\mathrm{O}_{2}$ & fosforilação oxidativa \\
\hline catalase & dismutação do $\mathrm{H}_{2} \mathrm{O}_{2}$ & defesa antioxidante \\
\hline ciclooxigenase & peroxidação ácido araquidónico & metabolismo de prostanoides \\
\hline citocromo $C$ & transferência de electrões & vários processos metabólicos \\
\hline hemoglobina & ligação de $\mathrm{O}_{2}$ & transporte de $\mathrm{O}_{2}$ no sangue \\
\hline \multicolumn{3}{|c|}{ Ferro não hémico } \\
\hline aconitase & isomerização do citrato & ciclo de Krebs \\
\hline ferredoxina & transferência de electrões & vários processos metabólicos \\
\hline superóxido dismutase / $\mathrm{Fe}^{\text {a }}$ & dismutação do $\mathrm{O}_{2} \cdot-$ & defesa antioxidante \\
\hline lipooxigenase & peroxidação de ácidos gordos & metabolismo ácidos gordos \\
\hline transferrina & ligação de Fe & transporte, homeostase do Fe \\
\hline \multicolumn{3}{|c|}{ Cobre } \\
\hline citocromo $c$ oxidase & redução do $\mathrm{O}_{2}$ & fosforilação oxidativa \\
\hline lacase & oxidação de fenois e derivados & metabolismo da lignina \\
\hline ascorbato oxidase & oxidação do ascorbato & metabolismo do ascorbato \\
\hline superóxido dismutase / Cu,Zn a & dismutação do $\mathrm{O}_{2}{ }^{\cdot-}$ & defesa antioxidante \\
\hline dopamina hidroxilase & hidroxilação da dopamina & metabolismo das catecolaminas \\
\hline plastocianina & transferência de electrões & vários processos metabólicos \\
\hline ceruloplasmina & ligação de $\mathrm{Cu}$ & transporte, homeostase do $\mathrm{Cu}$ \\
\hline hemocianina & ligação de $\mathrm{O}_{2}$ & transporte de $\mathrm{O}_{2}$ \\
\hline \multicolumn{3}{|c|}{ Molibdénio } \\
\hline xantina oxidase & hidroxilação da xantina & catabolismo das purinas, etc \\
\hline nitrato redutase & redução do $\mathrm{NO}_{3}^{-}$ & desnitrificação, assimilação, etc \\
\hline formato desidrogenase & redução $\mathrm{CO}_{2}$ /oxidação $\mathrm{HCO}_{2}^{-}$ & vias produtoras de energia \\
\hline nitrogenase / Mo, $\mathrm{Fe}^{\mathrm{b}}$ & redução de $\mathrm{N}_{2}$ a $\mathrm{NH}_{4}^{+}$ & fixação de azoto \\
\hline \multicolumn{3}{|c|}{ Manganês } \\
\hline piruvato oxidase & oxidação do piruvato & metabolismo do piruvato \\
\hline fosfoenolpiruvato carboxicinase & descarboxilação do oxaloacetato & gluconeogénese \\
\hline superóxido dismutase / $\mathrm{Mn}^{\mathrm{a}}$ & dismutação do $\mathrm{O}_{2}^{\cdot-}$ & defesa antioxidante \\
\hline arginase & conversão da arginina em ureia & ciclo da ureia \\
\hline \multicolumn{3}{|c|}{ Cobalto } \\
\hline carboxitransfosforilase & transferência do grupo fosfato & vários processos metabólicos \\
\hline
\end{tabular}


- continuação -

\begin{tabular}{|c|c|c|}
\hline nitrilo hidratase & hidratação de nitrilos a amidas & assimilação N e C \\
\hline metionina aminopeptidase & hidrólise do resíduo metionina & metabolismo das proteínas \\
\hline metiltransferase & transferência $-\mathrm{CH}_{3}$ & metabolismo de aminoácidos \\
\hline \multicolumn{3}{|c|}{ Níquel } \\
\hline urease & hidrólise da ureia a $\mathrm{NH}_{4}^{+}$ & catabolismo da ureia \\
\hline hidrogenase / Ni,Fe ${ }^{c}$ & oxidação de $\mathrm{H}_{2}$ / redução de $\mathrm{H}^{+}$ & vias produtoras de energia, etc \\
\hline CO desidrogenase & oxidação CO / redução de $\mathrm{CO}_{2}$ & vias prod. energia, fonte de C \\
\hline glioxalase I & isomerização & metabolismo do metilglioxal \\
\hline \multicolumn{3}{|c|}{ Zinco } \\
\hline anidrase carbónica & hidratação do $\mathrm{CO}_{2}$ & transporte $\mathrm{CO}_{2}$, controlo $\mathrm{pH}$, etc \\
\hline carboxipeptidase & hidrólise de péptidos & catabolismo de péptidos \\
\hline superóxido dismutase / Cu,Zn a & dismutação do $\mathrm{O}_{2}^{\cdot-}$ & defesa antioxidante \\
\hline álcool desidrogenase & oxidação de álcoois a aldeídos & metabolismo dos álcoois \\
\hline fosfatase alcalina & desfosforilação & vários processos metabólicos \\
\hline \multicolumn{3}{|c|}{ activação de enzimas e proteínas } \\
\hline \multicolumn{3}{|c|}{\begin{tabular}{|c|} 
Magnésio \\
\end{tabular}} \\
\hline enolase & desidratação fosfoenolpiruvato & glicólise \\
\hline piruvato carboxilase & carboxilação do piruvato & gluconeogénese \\
\hline ATPases & síntese/hidrólise de ATP & $\begin{array}{l}\text { produção de ATP, transporte de } \\
\text { solutos através de membranas }\end{array}$ \\
\hline \multicolumn{3}{|c|}{ Cálcio } \\
\hline calmodulina & ligação de $\mathrm{Ca}^{2+}$ & mensageiro metabolismo do Ca \\
\hline ATPases & síntese/hidrólise de ATP & $\begin{array}{l}\text { produção de ATP, transporte de } \\
\text { solutos através de membranas }\end{array}$ \\
\hline
\end{tabular}

a Existem diferentes tipos de superóxido dismutases: enzimas dependentes de cobre e zinco, presentes em eucariontes, enzimas dependentes de manganês, presentes em procariontes e na mitocôndria de eucariontes, e enzimas dependentes de ferro, presentes em procariontes.

${ }^{\mathrm{b}}$ Nitrogenase dependente de molibdénio e ferro.

c Hidrogenase dependente de níquel e ferro.

As geometrias frequentemente encontradas em Biologia não diferem muito das observadas nos compostos inorgânicos análogos, sendo frequentes arranjos octaédricos e tetraédricos, que podem apresentar distorções (Figura 3, Tabela 2).

Uma compreensão e discussão da utilização (escolha) da estrutura e da reactividade de iões metálicos como constituintes de centros catalíticos de enzimas pode ser feita com base em muitos dos conceitos da Química Inorgânica sobre coordenação e geometria de metais inseridos em compostos de coordenação. A constante de associação de metais em metaloproteínas e a facilidade de alteração de estado de oxidação são determinantes no comportamento dos centros metálicos descritos. A série dos metais de transição utilizada pela Biologia oferece uma enorme versatilidade de configurações electrónicas $\left(d^{1}\right.$ a $\left.d^{10}\right)$, estados de oxidação e estados de spin ( 0 a 5/2, para centros monometálicos, podendo ser detectados estados de spin mais elevados em agregados multimetálicos) (Tabela 3) [2-4]. Como se pode ver na Tabela 2, a escolha dos ligandos preferidos pelos diversos iões metálicos em sistemas biológicos, segue a previsão descrita na classificação dos metais de Arhland, Chatt e Davies [2-5].

\section{ProteínAs hÉmicas - hemo, uma estrutura Versátil}

O ferro é dos metais de transição o mais frequentemente utilizado pelos sistemas biológicos e pode ser encontrado em estruturas hémicas ou em centros contendo ferro não hémico (centros de ferro-enxofre e outros). A estrutura hémica (Figura 4-A) é uma das estruturas biológicas mais versáteis. $\mathrm{O}$ anel da porfirina, que disponibiliza quatro átomos de azoto para coordenar o ferro no plano equatorial, pode apresentar diferentes tipos de saturação (e.g., hemo $c$, hemo $b$, hemo $d_{1}$ e sirohemo (Figura 4-B)), podendo estar ou não ligado covalentemente à cadeia polipetídica (citocromos c ou citocromos de outros tipos, respectivamen- 


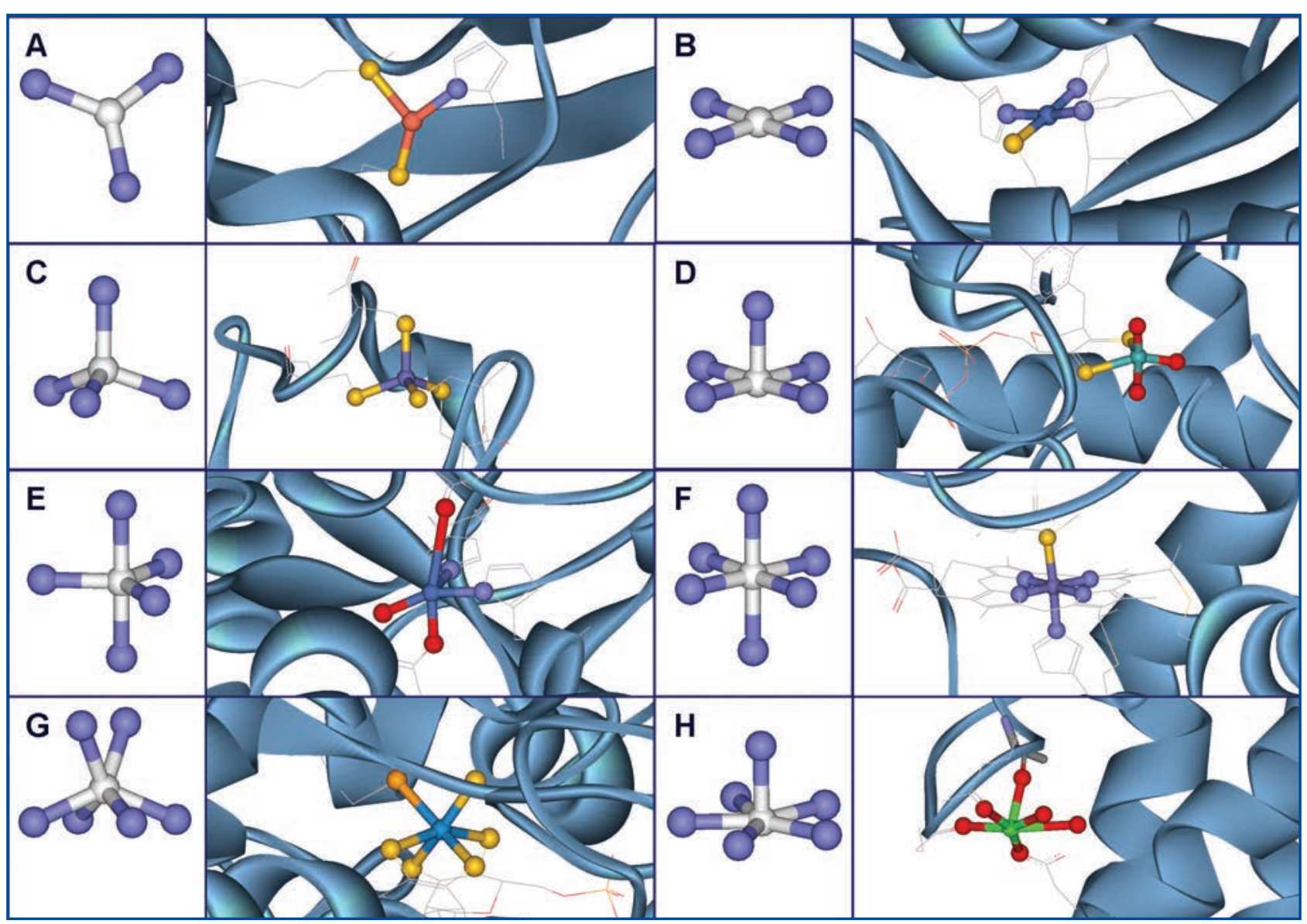

Figura 3 - Geometrias de coordenação mais frequentes em Biologia

Exemplos escolhidos mostrando o paralelismo entre as geometrias propostas pela Química Inorgânica e arranjos estruturais encontrados em metaloproteínas. (A) Trigonal plano - plastocianina (Cu coordenado por S(met), S(cis), N(his)). (B) Quadrangular plano - factor transcripcão dependente níquel (Ni coordenado por 3 N(his), S(cis)). (C) Tetraedro - rubredoxina (Fe coordenado por 4 S(cis)). (D) Pirâmide quadrada - aldeído oxidorredutase (Mo coordenado por 2 S(pterina), 3O(oxo)). (E) Bipirâmide triangular - urease (Ni coordenado por 2 N(his), O(gli), O(oxo), O(lis modif)). (F) Octaedro citocromo c (Fe coordenado por 4 N(porfirina IX), N(his), S(met). (G) Trigonal prismática - formato desidrogenase (W coordenado por 4 S(pterina), S(cis), Se(Se-cis)). (H) Pirâmide pentagonal - fosfolipase A2 (Ca coordenado por O(asp), 2 O(gli), O(tir), 2 O(oxo)). As imagens foram criadas com o programa Accelrys DS Visualizer v2.0 (Accelrys Software Inc.), com base nos ficheiros PDB 1BXV (plastocianina do choupo), 2Y3Y (factor de transcripção dependente de níquel de Helicobacter pylori), 2DSX (rubredoxina de Desulfovibrio gigas), 1VLB (aldeído oxidorredutase de Desulfovibrio gigas), 2KAU (urease de Klebsiella aerogenes), 3ZCF (citocromo $c$ humano), 1H0H (formato desidrogenase de Desulfovivrio gigas), 1KVW (fosfolipase A2 bovina); representam-se os átomos coordenantes como esferas e restantes átomos do centro metálico como linhas.

Tabela 3 - Estados de spin em metais de transição

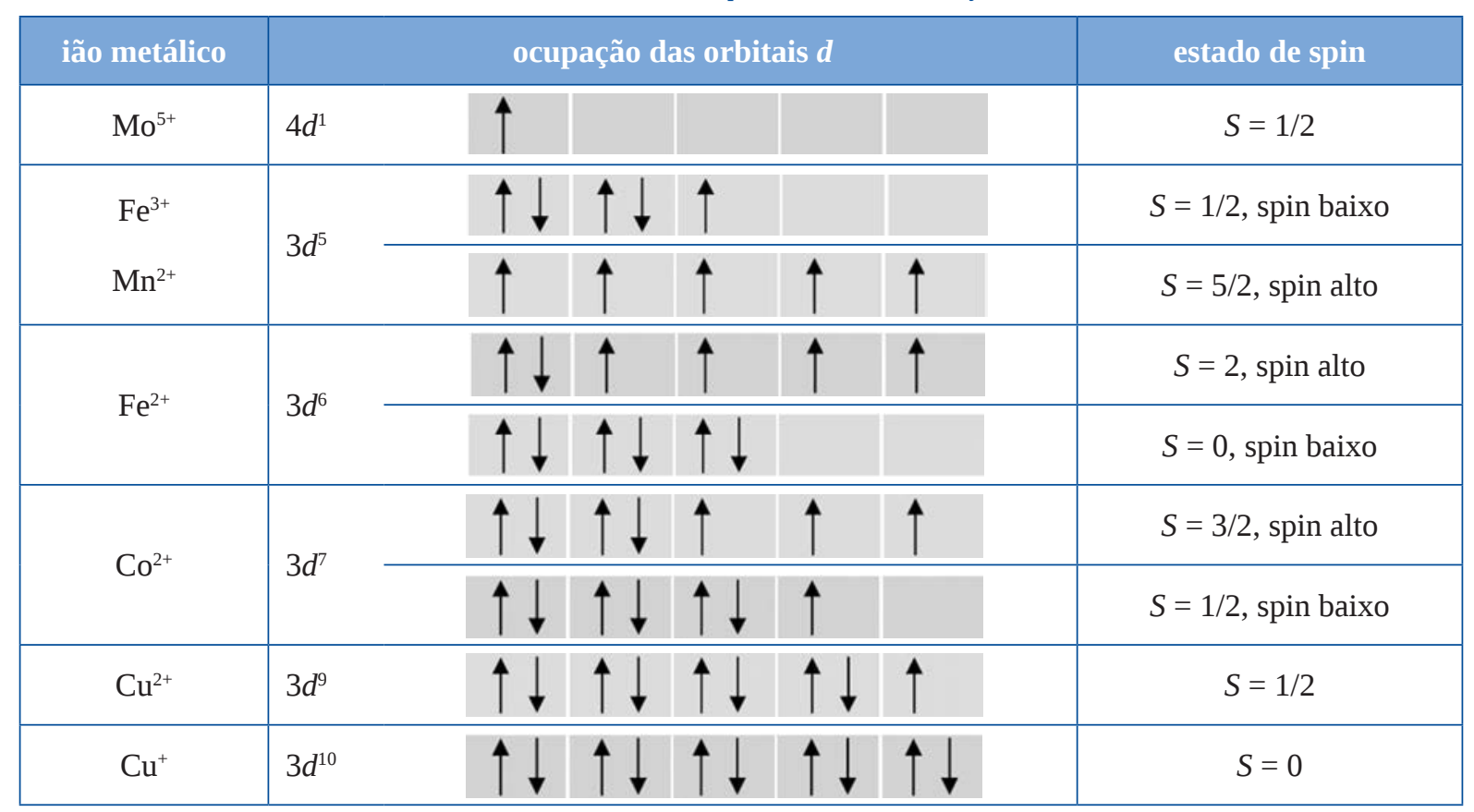


A

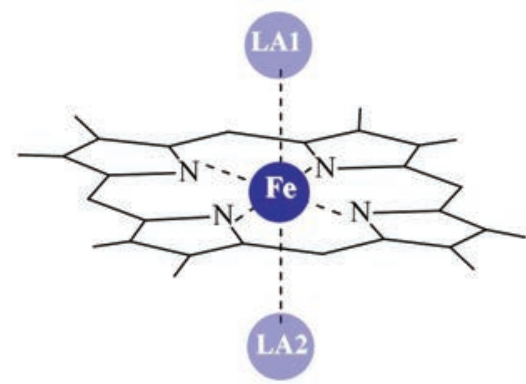

B

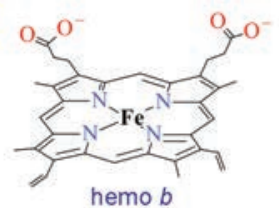

hemo $b$

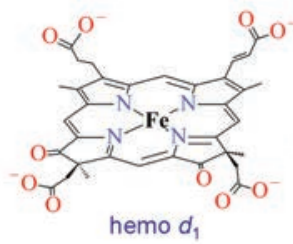

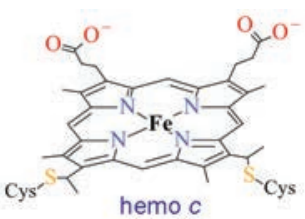

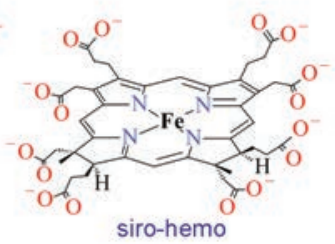

Figura 4 - Versatilidade de coordenação em estruturas hémicas

Variabilidade no tipo de porfirina (N-ligandos no plano equatorial) e ligandos axiais. (A) Estrutura base de um hemo: anel de porfirina e dois ligandos axiais (LA1 e LA2) coordenam um átomo de ferro. (B) Estruturas de diferentes hemos, mais frequentemente usados em biologia, hemos $b$, $c$, $d_{1}$ e siro-hemo. As imagens foram criadas com o programa Accelrys Draw 4.0 (Accelrys Software Inc.).

te). A versatilidade da estrutura hémica é ainda conseguida através da variabilidade de coordenação nas posições axiais (e.g., resíduos de metionina, histidina, cisteína, lisina, tirosina). Mais ainda, muitas destas propriedades podem ser moduladas pela exposição do hemo ao solvente, pela carga e constante dieléctrica da vizinhança. É de salientar que as proteínas hémicas, assim como outros grupos de metaloproteínas, são um exemplo claro de Química Supramolecular: a introdução do ferro na estrutura da porfirina e posterior inserção do hemo assim formado na cadeia polipetídica, a qual vai fornecer os ligandos axiais e locais de ligação covalente do hemo, resulta na formação concertada de um catalisador biológico cujas capacidades ultrapassam a de cada uma das partes individuais.

A porfirina e os ligandos axiais formam um centro hémico sujeito a um campo de ligandos, que, dependendo do tipo de átomos presentes nas posições axiais, pode ser fraco ou forte $[3,4]$. A biologia encontrou uma solução estrutural de grande versatilidade, como referimos, e usando dois dos estados de oxidação mais frequentes em biologia $\left(\mathrm{Fe}^{2+}, d^{6}, \mathrm{e} \mathrm{Fe}^{3+}, d^{5}\right)$ e diferentes desdobramentos energéticos das orbitais $d$ do metal (campo forte e campo fraco) obtêm-se quatro estados de spin, que podem ser atingidos só por modulação da vizinhança do átomo de ferro (Figura 5, Tabela 3). A riqueza estrutural e electrónica destes centros hémicos é ainda maior, pois os estados redox $\mathrm{Fe}^{4+}, d^{4}, \mathrm{e} \mathrm{Fe}^{5+}, d^{3}$, também são detectados em Biologia e existe ainda a possibilidade de se observarem estados de spin intermédios (equilíbrios de spin) [6,7].

Com base no tipo de porfirina, ligandos axiais presentes e covalência (ou não) estabelecida com a cadeia polipeptídica, foram reunidos, na Figura 6, seis casos paradigmáticos que contemplam estas questões (outros exemplos foram sistematizados na Tabela 4): (i) e (ii) Ferro hexacoordenado num hemo $c$, i.e., ferro com a esfera de coordenação completa num hemo ligado covalentemente à proteína: citocromo $c$ (coordenado por his, met) e citocromo $c_{7}$ (his, his), os quais exercem exclusivamente a função de transferência electrónica (Figura 6-A e 6-B); (iii) e (iv) Ferro hexacoordenado num

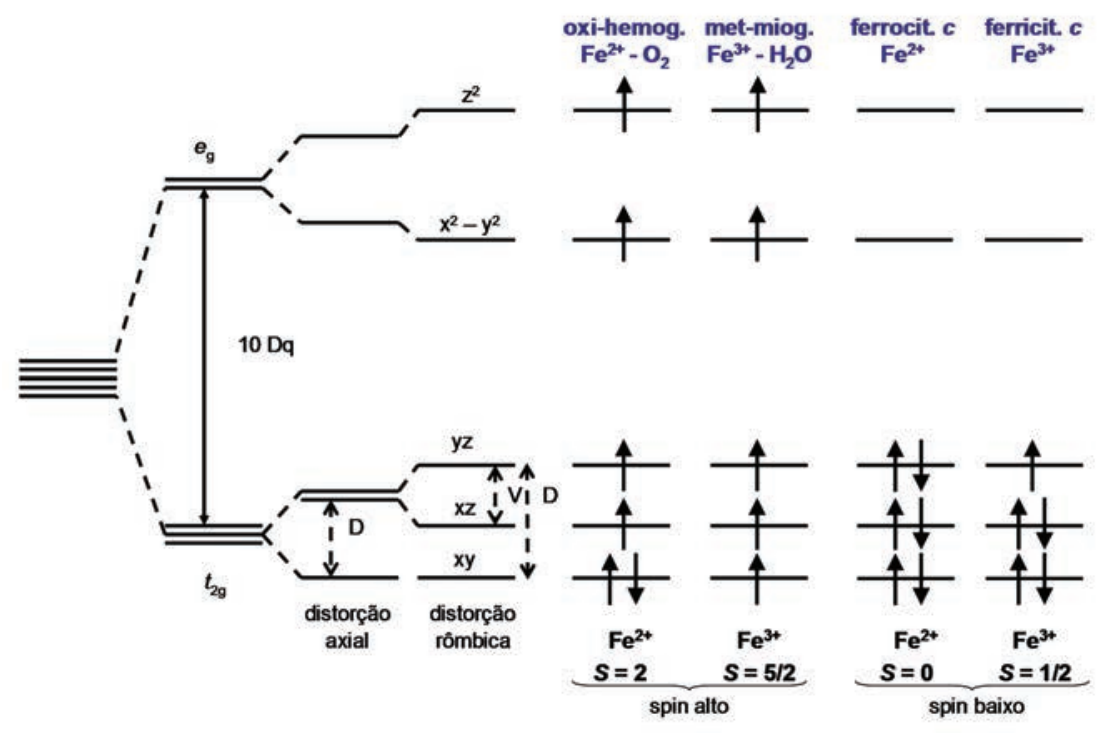

Figura 5 - Orbitais $d$, hemos / estados de oxidação e de spin

Energia das orbitais $d$ de hemo (porfirina IX-ferro) na presença de campo de ligandos fraco e forte, para dois estados de oxidação do metal. Oxi-hemog., oxi-hemoglobina $\left(\mathrm{Fe}^{2+}-\mathrm{O}_{2}\right)$; met-miog., meta-mioglobina $\left(\mathrm{Fe}^{3+}-\mathrm{H}_{2} \mathrm{O}\right)$; ferrocit. $c$, ferrocitocromo $\left(\mathrm{Fe}^{2+}\right)$; ferricit. $c$, ferricitocromo $\left(\mathrm{Fe}^{3+}\right)$. 


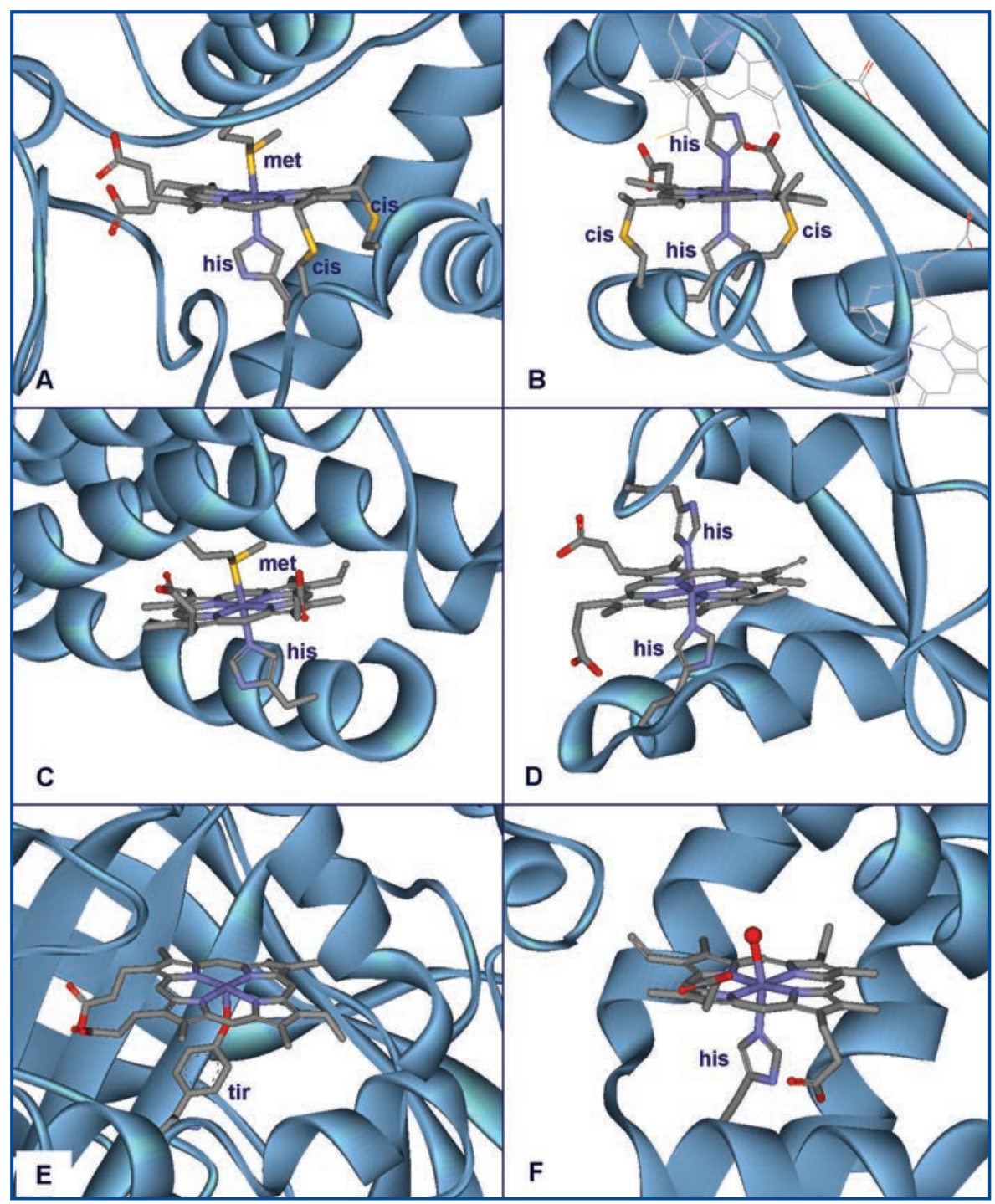

Figura 6 - Estruturas paradigmáticas do centro metálico de proteínas hémicas demonstrando a versatilidade de coordenação e funções biológicas

(A) Citocromo $c$, hemo $c$ (coordenado por his,met), ligado covalentemente à proteína, envolvido na transferência electrónica. (B) Citocromo $c_{7}$ (tri-hémico), hemo $c$ (his,his), ligado covalentemente, envolvido na transferência electrónica. (C) Citocromo $b_{562}$, hemo $b$ (his,met), ligado não covalentemente, envolvido na transferência electrónica. (D) Citocromo $b_{5}$, hemo $b$ (his,his), ligado não covalentemente, envolvido na transferência electrónica. (E) Catalase, hemo $b$ (tir, $\mathrm{H}_{2} \mathrm{O}_{2}$ ), catálise. (F) Mioglobina, hemo $b$ (his, $\mathrm{H}_{2} \mathrm{O}$ ), ligado não covalentemente, envolvido no transporte de oxigénio. As imagens foram criadas com o programa Accelrys DS Visualizer v2.0 (Accelrys Software Inc.), com base nos ficheiros PDB 3ZCF (citocromo c humano), 1HH5 (citocromo c7 de Desulfuromonas acetoxidans; os restantes dois hemos estão representados com linhas), 256B (citocromo b562 de Escherichia coli), 3NER (citocromo b5 humano), 1QQW (catalase do eritrócito humano), 1YMB (mioglobina de coração de cavalo). hemo b, i.e., ferro com a esfera de coordenação completa num hemo ligado não covalentemente: citocromo $b$ e $b_{562}$ (his, met e his, his), que exercem exclusivamente a função de transferência electrónica (Figura 6-C e 6-D); (v) e (vi) Ferro pentacoordenado e/ou coordenado por um sexto ligando lábil, num hemo $b$, i.e., esfera de coordenação incompleta num hemo ligado não covalentemente: catalase (tir, $\mathrm{H}_{2} \mathrm{O}_{2} / \mathrm{H}_{2} \mathrm{O}$ ) e mioglobina (his, $\mathrm{O}_{2}$ ), as quais têm capacidade catalítica (dismutação do $\mathrm{H}_{2} \mathrm{O}_{2}$ a $\mathrm{O}_{2}$ e $\mathrm{H}_{2} \mathrm{O}$ ) e funções específicas no transporte de oxigénio, respectivamente (Figura 6-E e 6-F). As proteínas hémicas com actividade catalítica serão discutidas em mais detalhe no ponto seguinte.

\section{Proteínas hémicas que são enzimas}

\subsection{EnZIMAS hÉmiCAS ISOLADAS EM ESTADOS NATIVOS ACTIVOS - A NITRITO REDUTASE DE DESULFOVIBRIO DESULFURICANS}

A redução de nitrito a amónio (processo biológico de amonificação dissimilativa) ocorre numa etapa única que envolve seis electrões (eq. 1) e é catalisada por uma proteína penta-hémica, a ccNIR [8].

$\mathrm{NO}_{2}^{-}+8 \mathrm{H}^{+}+6 \mathrm{e}^{-} \rightarrow \mathrm{NH}_{4}^{+}+2 \mathrm{H}_{2} \mathrm{O}$
A ccNIR de Desulfovibrio desulfuricans (oligómero com 2 subunidades, num arranjo $\alpha_{4} \beta_{2}$ ) contém cinco hemos tipo $c$ (na subunidade $\alpha$ ), que estão ligados de modo covalente à cadeia polipeptídica por ligações tioéter a resíduos de cisteína [9,10] (Figura 7). O hemo catalítico encontra-se na subunidade $\alpha$ e é o único hemo pentacoordenado, apresentando um só ligando proteico axial, um resíduo de lisina (identificado como hemo 1 (Figura 7)). Os outros quatro hemos da subunidade $\alpha$ são coordenados por duas histidinas, numa geometria octaédrica completa, sendo-lhes atribuídas funções de transferência de electrões do parceiro fisiológico para o centro activo. Assim, a análise estrutural indica que o hemo 1 é o único hemo com capacidade catalítica (interacção com substrato). A sexta posição deste hemo é ocupada por uma molécula de água na estrutura cristalina. Este é um exemplo de uma proteína hémica isolada numa forma activa [7,9].

\subsection{ENZIMAS HÉMICAS ISOLADAS EM FORMAS INACTIVAS E QUE REQUEREM ACTIVAÇÃO}

As enzimas hémicas que são discutidas nesta secção são normalmente isoladas em estados inactivos, mas podem ser activadas através de um passo que envolve alterações conformacionais importantes, que resultam na formação de um centro catalítico competente, que pode interactuar com 
Tabela 4 - Proteínas hémicas: ligandos axiais, reacções mediadas e funções biológicas

\begin{tabular}{|c|c|c|}
\hline proteína & ligandos axiais & $\begin{array}{l}\text { função } \\
\text { reacção }\end{array}$ \\
\hline $\begin{array}{l}\text { citocromo } b \\
\text { (hemo } b \text { ) }\end{array}$ & his, his & $\begin{array}{c}\text { transferência de electrões } \\
\left(\text { cit. b) } \mathrm{Fe}^{3+}+1 \mathrm{e}-\rightleftharpoons \text { (cit. } b\right) \mathrm{Fe}^{2+}\end{array}$ \\
\hline $\begin{array}{c}\text { citocromo } c \\
(\text { hemo } c)\end{array}$ & his, met & $\begin{array}{c}\text { transferência de electrões } \\
(\text { cit. } c) \mathrm{Fe}^{3+}+1 \mathrm{e}-\rightleftharpoons \text { (cit. } c \text { ) } \mathrm{Fe}^{2+}\end{array}$ \\
\hline $\begin{array}{l}\text { citocromo } c_{550} \\
\quad(\text { hemo } c)\end{array}$ & his, met & $\begin{array}{l}\text { transferência de electrões } \\
(\text { cit. } c) \mathrm{Fe}^{3+}+1 \mathrm{e}-\rightleftharpoons \text { (cit. } c \text { ) } \mathrm{Fe}^{2+}\end{array}$ \\
\hline $\begin{array}{l}\text { citocromo } c_{552} \\
\quad(\text { hemo } c)\end{array}$ & his, met & $\begin{array}{l}\text { transferência de electrões } \\
\text { (cit. c) } \mathrm{Fe}^{3+}+1 \mathrm{e}-\stackrel{\text { (cit. } c \text { ) } \mathrm{Fe}^{2+}}{ }\end{array}$ \\
\hline $\begin{array}{l}\text { hemoglobina } \\
\text { (hemo } b \text { ) }\end{array}$ & his, $\mathrm{O}_{2} / \mathrm{H}_{2} \mathrm{O}$ & transporte de oxigénio \\
\hline $\begin{array}{l}\text { peroxidase } \\
\text { (hemo } b \text { ) }\end{array}$ & his, $\mathrm{H}_{2} \mathrm{O}_{2} / \mathrm{H}_{2} \mathrm{O}$ & $\begin{array}{c}\text { remoção do } \mathrm{H}_{2} \mathrm{O}_{2} \\
\mathrm{~A}-\mathrm{H}_{2}+\mathrm{H}_{2} \mathrm{O}_{2}+\mathrm{H}^{+} \rightarrow \mathrm{A}+2 \mathrm{H}_{2} \mathrm{O}\end{array}$ \\
\hline $\begin{array}{l}\text { cloroperoxidase } \\
\text { (hemo } b \text { ) }\end{array}$ & cis, $\mathrm{H}_{2} \mathrm{O}_{2} / \mathrm{H}_{2} \mathrm{O}$ & $\begin{array}{c}\text { remoção do } \mathrm{H}_{2} \mathrm{O}_{2} \\
\mathrm{~A}-\mathrm{H}+\mathrm{X}^{-}+\mathrm{H}_{2} \mathrm{O}_{2} \rightarrow \mathrm{A}-\mathrm{X}+\mathrm{H}_{2} \mathrm{O}\end{array}$ \\
\hline $\begin{array}{l}\text { catalase } \\
\text { (hemo b) }\end{array}$ & tir, $\mathrm{H}_{2} \mathrm{O}_{2} / \mathrm{H}_{2} \mathrm{O}$ & $\begin{array}{c}\text { remoção do } \mathrm{H}_{2} \mathrm{O}_{2} \\
2 \mathrm{H}_{2} \mathrm{O}_{2} \rightarrow 2 \mathrm{H}_{2} \mathrm{O}+\mathrm{O}_{2}\end{array}$ \\
\hline $\begin{array}{l}\text { óxido nítrico sintase } \\
\text { (hemo } b \text { ) }\end{array}$ & cis, arginina $/ \mathrm{H}_{2} \mathrm{O}$ & $\begin{array}{c}\text { síntese de óxido nítrico } \\
\text { arginina }+2 \mathrm{O}_{2}+3 / 2 \mathrm{NADPH} \rightarrow \\
\text { citrulina }+{ }^{\cdot} \mathrm{NO}+2 \mathrm{H}_{2} \mathrm{O}+3 / 2 \mathrm{NADP}^{+}\end{array}$ \\
\hline $\begin{array}{l}\text { sistema microssomal } \mathrm{P}_{450} \\
(\text { hemo } b)\end{array}$ & cis, $\mathrm{RH} / \mathrm{H}_{2} \mathrm{O}$ & $\begin{array}{c}\text { metabolismo de xenobióticos, etc } \\
\mathrm{RH}+\mathrm{O}_{2}+2 \mathrm{e}-+2 \mathrm{H}^{+} \rightarrow \mathrm{ROH}+\mathrm{H}_{2} \mathrm{O}\end{array}$ \\
\hline $\begin{array}{l}\text { nitrito redutase } \\
\quad \text { (hemo } c \text { ) }\end{array}$ & lis, $\mathrm{NO}_{2}{ }^{-} / \mathrm{H}_{2} \mathrm{O}$ & $\begin{array}{l}\text { redução dissimilativa de nitrito } \\
\mathrm{NO}_{2}^{-}+6 \mathrm{e}^{-}+8 \mathrm{H}^{+} \rightarrow \mathrm{NH}_{4}^{+}+2 \mathrm{H}_{2} \mathrm{O}\end{array}$ \\
\hline $\begin{array}{l}\text { nitrito redutase } \\
\left.\text { (hemo } d_{1}\right)\end{array}$ & his, $\mathrm{NO}_{2}^{-} / \mathrm{H}_{2} \mathrm{O}$ & $\begin{array}{c}\text { redução dissimilativa de nitrito } \\
\mathrm{NO}_{2}^{-}+1 \mathrm{e}^{-}+2 \mathrm{H}^{+} \rightarrow \cdot \mathrm{NO}+\mathrm{H}_{2} \mathrm{O}\end{array}$ \\
\hline $\begin{array}{l}\text { hidroxilamina oxidorredutase } \\
\text { (hemo } \mathrm{P}_{460} \text { ) }\end{array}$ & his, $\mathrm{NH}_{2} \mathrm{OH} / \mathrm{H}_{2} \mathrm{O}$ & $\begin{array}{c}\text { nitrificação } \\
\mathrm{NH}_{2} \mathrm{OH}+\mathrm{H}_{2} \mathrm{O} \rightarrow \mathrm{NO}_{2}^{-}+4 \mathrm{e}^{-}+5 \mathrm{H}^{+}\end{array}$ \\
\hline $\begin{array}{l}\text { nitrito redutase } \\
\text { e sulfito redutase } \\
\text { (siro-hemo) }\end{array}$ & cis, $\mathrm{NO}_{2}^{-}-\mathrm{H}_{2} \mathrm{O}$ & $\begin{array}{l}\text { redução assimilativa de nitrito } \\
\mathrm{NO}_{2}^{-}+6 \mathrm{e}-+8 \mathrm{H}^{+} \rightarrow \mathrm{NH}_{4}^{+}+2 \mathrm{H}_{2} \mathrm{O} \\
\mathrm{SO}_{3}^{2-}+6 \mathrm{e}-+6 \mathrm{H}^{+} \rightarrow \mathrm{S}^{2-}+3 \mathrm{H}_{2} \mathrm{O}\end{array}$ \\
\hline
\end{tabular}

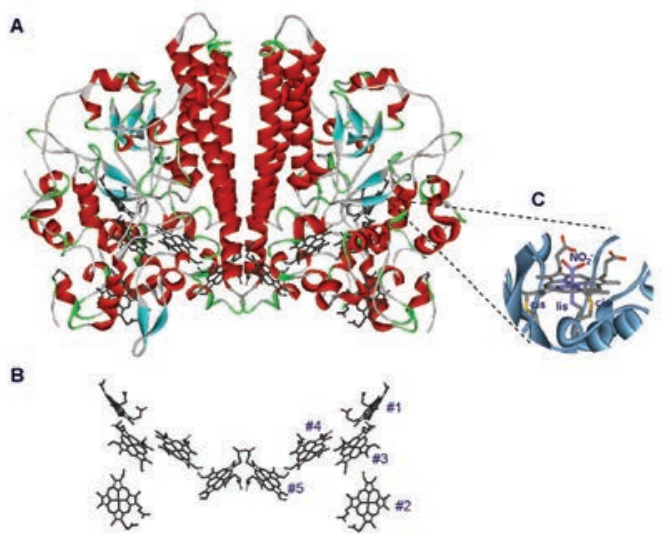

Figura 7 - Estrutura da subunidade $\alpha$ da ccNIR de Desulfovibrio desulfuricans

(A) A estrutura do dímero é colorida pelos elementos de estrutura secundária. Os hemos são visualizados a preto. (B) Representação dos hemos na mesma orientação do painel A. Os hemos numerados de 2 a 5 têm coordenação axial (his,his) e o hemo 1 é coordenado por (lis, $\mathrm{H}_{2} \mathrm{O}$ ). (C) Detalhe da coordenação do centro catalítico activo (hemo 1). Figuras obtidas usando o DS Visualizer v2.0. (Accelrys Software Inc.), com base no ficheiro PDB 1OAH. o substrato. O processo de activação é complexo e a esfera de coordenação do ferro hémico tem de ser controlada de modo a que a reacção só ocorra na presença de poder redutor suficiente (controlo estrutural e redox).

Os dois exemplos escolhidos têm pontos em comum. A estrutura terciária é desenhada de modo a conter um centro de transferência electrónica e um centro catalítico inactivo quando isolado, mas competente após activação. Neste caso, os processos de transferência electrónica são complexos e pode ocorrer um processo intermolecular entre a enzima e o doador/aceitador electrónico e outro intramolecular entre os dois hemos presentes na mesma subunidade enzimática. Nestes exemplos, a forma inactiva da enzima apresenta uma esfera de coordenação completa, mas a remoção de um ligando origina formas de menor número de coordenação que podem ligar substratos.

\subsubsection{A nitrito Redutase de Paracoccus denitrificans}

A redução do nitrito tem um lugar importante no biociclo do azoto, participando em várias vias metabólicas [11]. 
Uma dessas vias, de enorme importância ambiental e industrial, é a desnitrificação através da qual o nitrato é reduzido a azoto (eq. 2) [12-16].

$2 \mathrm{NO}_{3}^{-}+10 \mathrm{e}^{-}+12 \mathrm{H}^{+} \rightarrow \mathrm{N}_{2}+6 \mathrm{H}_{2} \mathrm{O}$

A reacção global (eq. 3) compreende quatro etapas sucessivas,

$\mathrm{NO}_{3}^{-} \rightarrow \mathrm{NO}_{2}^{-} \rightarrow{ }^{-} \mathrm{NO} \rightarrow \mathrm{N}_{2} \mathrm{O} \rightarrow \mathrm{N}_{2}(\mathrm{~g})$

sendo conhecidas estruturalmente todas as metaloenzimas envolvidas (eq. 4 a 7 ).

$\mathrm{NO}_{3}^{-}+2 \mathrm{e}^{-}+2 \mathrm{H}^{+} \stackrel{\text { nitrato redutase }}{\mathrm{Mo}, \mathrm{Fe}} \mathrm{NO}_{2}^{-}+\mathrm{H}_{2} \mathrm{O}$

$\mathrm{NO}_{2}^{-}+\mathrm{e}^{-}+2 \mathrm{H}^{+} \stackrel{\text { nitrito redutase }}{\text { Fe ou } \mathrm{Cu}} \cdot \mathrm{NO}+\mathrm{H}_{2} \mathrm{O}$

$2 \mathrm{NO}+2 \mathrm{e}^{-}+2 \mathrm{H}^{+} \stackrel{\text { óxido nítrico redutase }}{\mathrm{Fe}} \mathrm{N}_{2} \mathrm{O}+\mathrm{H}_{2} \mathrm{O}$

$\mathrm{N}_{2} \mathrm{O}+2 \mathrm{e}^{-}+2 \mathrm{H}^{+} \stackrel{\text { óxido nitroso redutase }}{\stackrel{\mathrm{Cu}}{\longrightarrow}} \mathrm{N}_{2}+\mathrm{H}_{2} \mathrm{O}$

Em Paracoccus denitrificans, a redução de nitrito a óxido nítrico (eq. 5) é levada a cabo pela cd NIR. Esta é uma proteína hémica dimérica e cada monómero é constituído por dois domínios diferentes (Figura 8) [16]. Um dos domínios liga de modo covalente um hemo $c$ e o outro contém um hemo $d_{1}$ ligado de forma não covalente. O hemo $c$ apresenta o átomo de ferro hexacoordenado e tem um papel na transferência de electrões do parceiro fisiológico para o centro activo (como antecipado pela coordenação octaédrica). O hemo $d_{1}$ é o centro catalítico.

A cd $_{1}$ NIR de Paracoccus denitrificans é isolada numa forma inactiva. Após a redução do hemo $c$ ocorrem alterações estruturais importantes em toda a proteína, as quais conduzem à activação da enzima. (i) Na forma oxidada, a esfera de coordenação do ferro do hemo $d_{1}$ está completamente ocupada por uma tirosina e uma histidina como ligandos axiais, o que explica a inactivação da enzima $[17,18]$. (ii) Após a redução, a cadeia lateral da tirosina é deslocada e o hemo $d_{1}$, agora pentacoordenado, está pronto para interactuar com o substrato (a molécula de nitrito coordenada pelo átomo de azoto pode ser visualizada na estrutura cristalina, assim como o produto, o óxido nítrico (Figura 8)) [17]. (iii) O hemo $c$, embora se mantenha hexacoordenado, sofre igualmente uma alteração na coordenação axial: enquanto que na forma oxidada o ferro se encontra coordenado por duas histidinas, na forma reduzida a coordenação passa a ser feita por uma histidina e uma metionina. Esta alteração conformacional é concertada com a alteração do número de coordenação do hemo $d_{1}$ [17,19-21].
4.2.2. A peroxidase bacteriana (DI-HÉmica) de Marinobacter hidRoCARBONOCLASTICUS

As CCP isoladas de bactérias são proteínas diméricas que catalisam a redução de peróxido de hidrogénio a água (eq. 8) [22].

$\mathrm{H}_{2} \mathrm{O}_{2}+2 \mathrm{e}^{-}+2 \mathrm{H}^{+} \rightarrow 2 \mathrm{H}_{2} \mathrm{O}$

Cada monómero contém dois hemos $c$ com funções distintas: transferência electrónica e catálise (Figura 9) [23-25]. Na maioria dos casos, esta enzima é isolada numa forma inactiva, em que ambos os hemos são hexacoordenados: o hemo de transferência electrónica tem como ligandos axiais um resíduo de metionina e outro de histidina e o hemo peroxidático dois resíduos de histidina. O processo de activação requer poder redutor e a presença de iões cálcio [22].

A redução do hemo de transferência electrónica é acoplada a uma alteração conformacional muito relevante na proximidade do hemo peroxidático: este centro perde um dos ligandos histidinilo e torna-se pentacoordenado e com capacidade de ligar o substrato [26,27].

Na ausência de iões cálcio, a conversão do hemo peroxidático a pentacoordenado não ocorre e a enzima permanece inactiva.

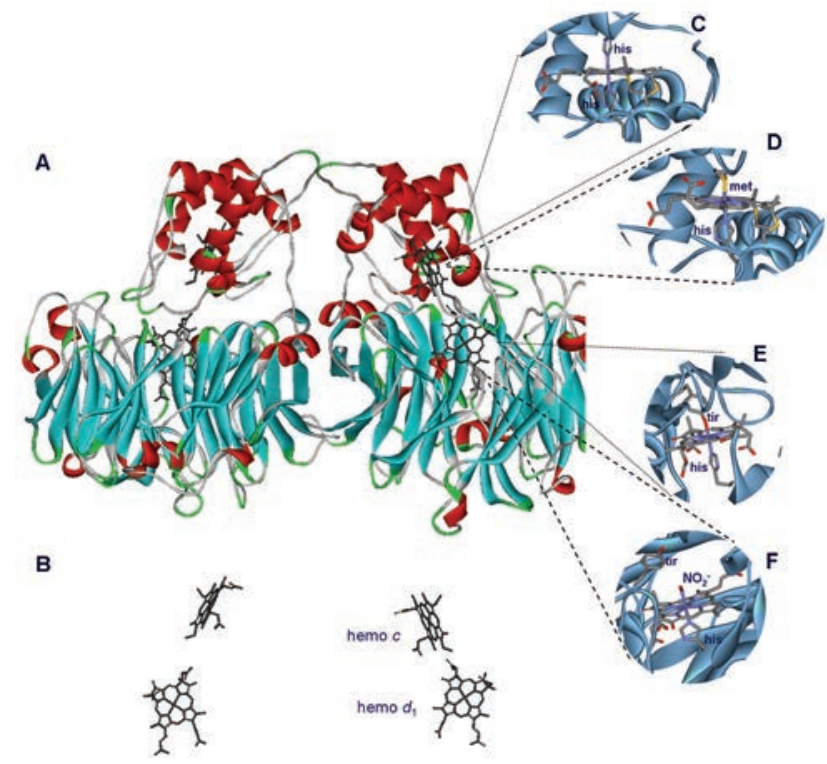

Figura 8 - Estrutura da cd NIR de Paracoccus denitrificans

(A) Estrutura do dímero da cd $_{1}$ NIR na forma inactiva, oxidada; a estrutura está colorida de acordo com os de estrutura secundária. Os hemos são visualizados a preto. (B) Representação dos hemos na mesma orientação do painel A. (C) Detalhe da coordenação do hemo $c$ na forma inactiva, oxidada (his,his). (D) Detalhe da coordenação do hemo c na forma activa, reduzida (his,met). (E) Detalhe da coordenação do hemo $d_{1}$ na forma inactiva, oxidada (his,tir). (F) Detalhe da coordenação do hemo $d_{1}$ na forma activa, reduzida (his, $\mathrm{NO}_{2}{ }^{-}$), com evidente remoção da tir da esfera de coordenação, criando uma posição vaga de coordenação, potencial local de interacção com o substrato. Figuras obtidas usando o DS Visualizer v2.0. (Accelrys Software Inc.), com base nos ficheiros PDB 1QKS (painéis A, B, C e E) e 1AOF (painéis D e F). 


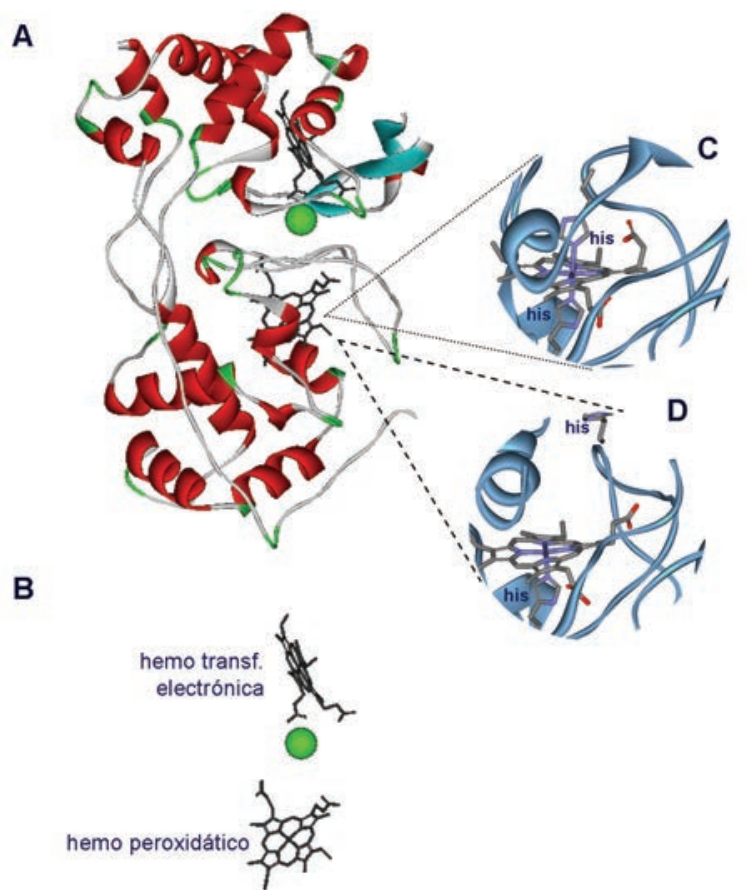

Figura 9 - Estrutura do monómero da CCP de Marinobacter hydrocarbonoclasticus

(A) Estrutura do monómero da CCP na forma activa; a estrutura é colorida pelos elementos de estrutura secundária. Os hemos são visualizados a preto e o átomo de cálcio a verde. (B) Representação dos hemos e do cálcio na mesma orientação do painel A. (C) Detalhe da coordenação do hemo peroxidático na forma inactiva (his,his). (D) Detalhe da coordenação do hemo peroxidático na forma activa (his, $\mathrm{H}_{2} \mathrm{O}$ ); a ligação do cálcio induz uma alteração conformacional que conduz à transformação do hemo inactivo em activo através da remoção da his. Figuras obtidas usando o DS Visualizer v2.0. (Accelrys Software Inc.), com base nos ficheiros PDB 1RZ6 (painéis A, B e C) e 1RZ5 (painel D).

\section{Conclusões}

Os exemplos discutidos demonstram que os sistemas hémicos têm grande diversidade e versatilidade: usando uma estrutura básica comum que adaptou variações subtis (conforme mostrado na utilização do hemo $c$, hemo $b$ e hemo d), o hemo pode estar ligado, ou não, de modo covalente à cadeia polipeptídica, pode incorporar uma variedade de ligandos em posições axiais e alterar o número de coordenação, os estados de oxidação e spin. Outras variações desta estrutura básica são exploradas pela Biologia e podem incorporar níquel (coenzima $\mathrm{F}_{430}$ da metil-coenzima $\mathrm{M}$ redutase envolvido na oxidação anaeróbia de metano) [28], cobalto (corrina na vitamina $B_{12}$ ) e magnésio (clorina nas clorofilas) [5].

Estas estruturas modulares são muitas vezes usadas em Biologia, como blocos construtores de centros activos, resultado de processos evolutivos e de conservação/optimização de energia metabólica. Um outro caso paradigmático é o dos centros de ferro-enxofre, onde estruturas tetraédricas básicas de $\mathrm{Fe}(\mathrm{S})_{4}$ permitem uma grande variabilidade estrutural de agregados e de nuclearidade [29].

O nosso objectivo neste artigo foi demonstrar que a esfera de coordenação "desenhada" pelos ligandos em torno do metal nos centros catalíticos de enzimas controla a actividade enzimática. Grande parte das metaloproteínas são isoladas em estados inactivos e para promoverem a catálise requerem uma etapa de activação. Para gerar um sítio catalítico é necessário poder redutor, alterações de estado de oxidação e spin, incubação com substratos e algumas vezes a presença de iões externos. Estes processos conduzem a importantes alterações conformacionais que levam ao design de um centro catalítico competente. Os exemplos indicados, demonstram claramente o controlo da esfera de coordenação do metal na actividade enzimática e, mais ainda, a dinâmica da transformação de espécies inactivas com consequentes rearranjos estruturais.

Foi identificada uma estratégia comum e unificadora: esferas de coordenação completas não podem catalisar reacções e formas activas podem ser obtidas por alteração do número de coordenação, e demonstrado que ligandos e electrões podem modular a actividade de metaloproteínas e que muitas das noções da Química de Coordenação são aplicáveis à Bioquímica. Os exemplos descritos representam casos elucidativos. Proteínas de baixa massa molecular, que actuam em processos de transferência electrónica, não alteram a esfera de coordenação do seu centro activo. O seu hemo altera o estado de oxidação sem alterar o número de coordenação. Em condições fisiológicas, o número de coordenação não é alterado e a porfirina e os ligandos axiais têm um papel determinante no potencial redox operacional. Foi descrito também que existem casos que não requerem activação, pois a esfera de coordenação tem disponibilidade para coordenar o(s) substrato(s) (ccNIR de Desulfovibrio desulfuricans). Outras proteínas são isoladas em estados inactivos onde o centro reaccional apresenta uma esfera de coordenação completa. A remoção de um ligando crucial dá origem a um local para a ligação do substrato. Na maioria dos casos estas alterações de coordenação são acompanhadas de modificações estruturais drásticas.

Estas noções são reforçadas pelos exemplos listados na Tabela 4, onde, para diferentes proteínas hémicas, se podem correlacionar tipos de coordenação/ligandos axiais com tipos de reaç̧ão (transferência electrónica ou actividade enzimática) e funções biológicas.

Muitos dos argumentos apresentados podem ser aplicados ao desempenho de outros metais de transição utilizados por sistemas biológicos. A Tabela 5 recolhe informação sobre estados activos e inactivos de metaloenzimas, onde a alteração do número de coordenação é evidente, usando os conceitos gerais observados em proteínas hémicas. O mesmo tipo de aproximação é aplicável na interpretação de correlações estrutura/actividade de muitas enzimas e agora explícito em (i) proteínas contendo ferro não hémico, como as superóxido redutases e hidrogenases dependentes de níquel e ferro, (ii) proteínas contendo cobre, nitrito redutases e óxido nitroso redutase, e (iii) enzimas contendo centros mononucleares de molibdénio e tungsténio.

As enzimas contendo molibdénio e tungsténio apresentam possibilidades de esferas de coordenação flexíveis (em ge- 
Tabela 5 - Estados activos e inactivos em metaloenzimas: evidência para alteração do número de coordenação

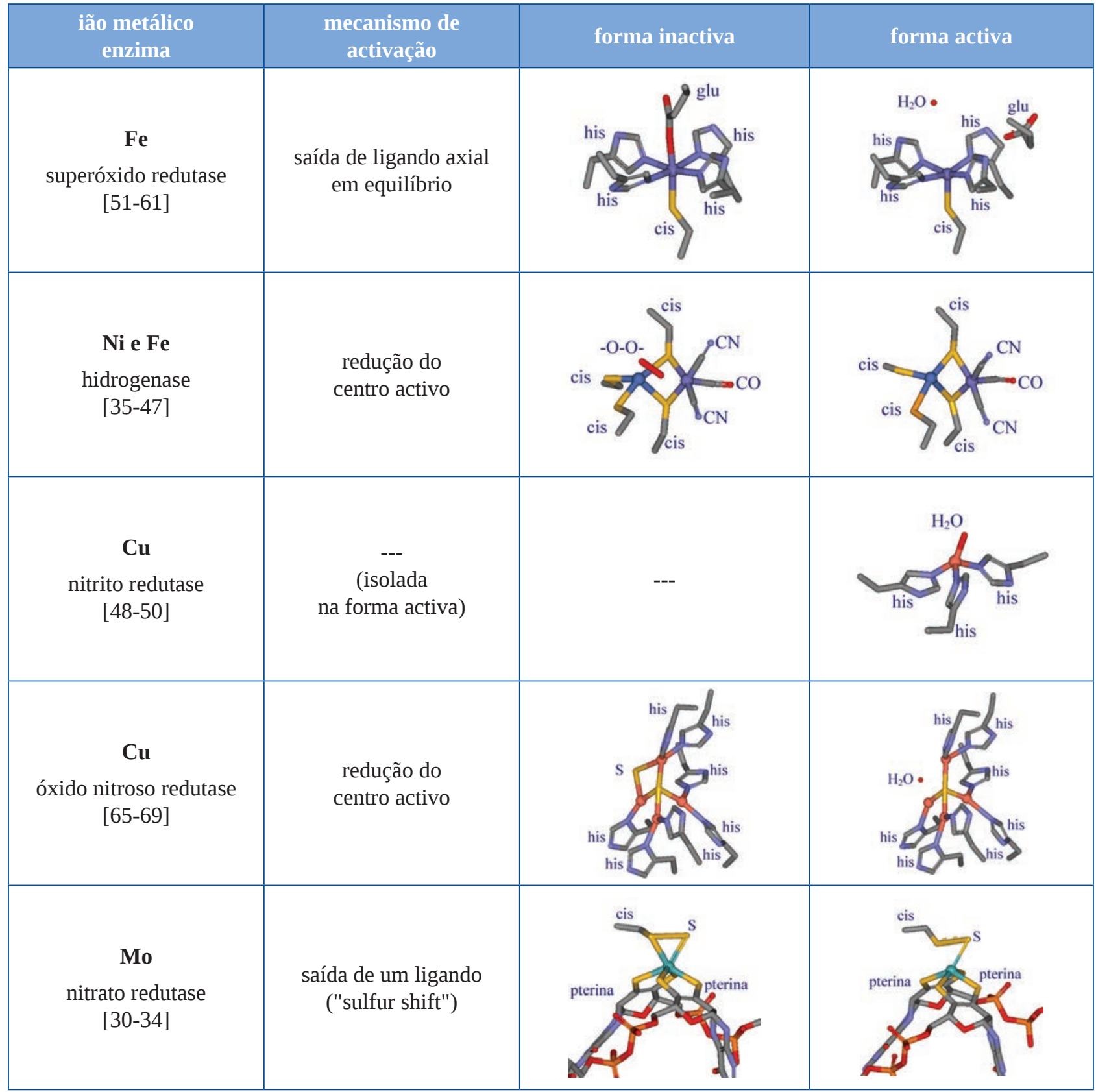

ral com ligandos pterínicos), elevados números de coordenação, que estabilizam vários estados de oxidação, e elevada afinidade para átomos de oxigénio e enxofre. Esferas de coordenação incompletas introduzem flexibilidade na interacção com substratos e proporcionam a estas enzimas um modo expedito para inserir ou abstrair átomos, na maioria dos casos de oxigénio, conforme se pode observar nas propostas mecanísticas das molibdoenzimas aldeído oxidorredutase e xantina oxidase, nitrato redutase, CO desidrogenase e sulfito oxidase [30-34]. Do mesmo modo, é claro que a activação em hidrogenases dependentes de níquel e ferro requer a remoção de ligandos do centro catalítico, isolado em geral numa forma inactiva [35-47]. A redução do nitrito levada a cabo em etapas desnitrificantes por enzimas contendo cobre (eq. 5) revela, após a análise estrutural, que o centro catalítico (coordenado por três ligandos proteicos (his) e uma molécula de água (grupo lábil)) se encontra num estado activo e não requer activação [48-50].
No caso das superóxido redutases, é bem evidente uma regulação fina conduzida por um grupo "axial”. O centro catalítico contendo ferro não hémico está coordenado por quatro átomos de azoto (his) localizados num "plano equatorial”; uma cisteina e um glutamato completam a esfera de coordenação. O ligar/desligar do resíduo de glutamato regula a actividade e pode ser um interruptor sensível ao $\mathrm{pH}$ do meio reaccional [51-61].

Mais ainda, o controlo exercido pela esfera de coordenação do metal, aqui demonstrado, no controlo de estados de activação de metaloproteínas (activo versus inactivo), tem maior generalidade, proporcionando mecanismos que permitem à célula alterar a actividade/função de uma proteína. A participação do citocromo $c$ na apoptose constitui um dos exemplos mais bem documentado deste mecanismo [62-64]: através de alteração da esfera de coordenação, de hexa para pentacoordenada, desencadeada por interacções 
com lípidos aniónicos, o citocromo $c$ mitocondrial altera a sua função de transferência electrónica para catálise (peroxidase). Este mecanismo de regulação da função de biomoléculas aumenta e amplifica ainda mais a importância da Química de Coordenação na compreensão de processos bioquímicos.

\section{AgradeCIMENTOS}

Os autores agradecem o apoio financeiro concedido pela Fundação para a Ciência e Tecnologia/MEC (PTDC/QUI-BIQ/100366/2008, PTDC/BIA-PRO/109796/2009, PTDC/ QUI-BIQ/116481/2010, e PEst-C/EQB/ LA0006/2013).

\section{REFERÊNCIAS}

[1] I. Moura, S.R. Pauleta, J.J.G. Moura, J. Biol. Inorg. Chem. 13 (2008) 1185-1195

[2] J.J.R. Fraústo da Silva, R.J.P. Williams, "The Biological Chemistry of the Elements: The Inorganic Chemistry of Life”, Oxford University Press, Oxford, 2001

[3] N.N. Greenwood, A. Earnshaw, "Chemistry of the Elements”, Pergamon Press Ldta, Oxford, 1984

[4] K.F. Purcell, J.C. Kotz, "Inorganic chemistry”, W.B. Saunders Company, Philadelphia, 1977

[5] I. Bertini, H.B. Gray, E. Stiefel, J. Valentine, "Biological Inorganic Chemistry: Structure and Reactivity”, University Science Books, Los Angeles, 2007

[6] G. Palmer, Biochem. Soc. Trans. 13 (1985) 548-560

[7] G.R. Moore, G.W. Pettigrew, "Cytochromes c - Evolutionary, structural and physicochemical aspects”, Springer, Ber$\lim , 1990$

[8] B. Burlat, J.D. Gwyer, S. Poock, T. Clarke, J.A. Cole, A.M. Hemmings, M.R. Cheesman, J.N. Butt, D.J. Richardson, Biochem. Soc. Trans. 33 (2005) 137-140

[9] M.G. Almeida, S. Macieira, L. Gonçalves, R. Huber, C.A. Cunha, M.J. Romão, C. Costa, J. Lampreia, J.J.G. Moura, I. Moura, Eur. J. Biochem. 207 (2003) 3904-3915

[10] C.A. Cunha, S. Macieira, J.M. Dias, G. Almeida, L.L. Goncalves, C. Costa, J. Lampreia, R. Huber, J.J.G. Moura, I. Moura, M.J. Romão, J. Biol. Chem. 278 (2003) 1745517465

[11] R.M. Martínez-Espinosa, J.A. Cole, D.J. Richardson, N.J. Watmough, Biochem. Soc. Trans. 39 (2011) 175-178

[12] M. Kobayashi, Y. Matsuo, A. Takimoto, S. Suzuki, F. Maruo, H. Shoun J. Biol. Chem 271 (1996) 16263-16267

[13] W.G. Zumft, Microbiol. Mol. Biol. Rev. 61 (1997), 533-616

[14] I. Moura, J.J.G. Moura, Curr. Opin. Chem. Biol. 5 (2001) 168-175

[15] O. Einsle, P.M. Kroneck, Biol. Chem. 385 (2004) 875-900

[16] W.G. Zumft, P.M. Kroneck, Adv. Microb. Physiol. 52 (2007) $107-227$

[17] V. Fulop, J.W. Moir, S.J. Ferguson, J. Hajdu, Cell 81 (1995) 369-377
[18] P.A. Williams, V. Fulop, E.F. Garman, N.F. Saunders, S.J. Ferguson, J. Hajdu, Nature 389 (1997) 406-412

[19] D. Nurizzo, M.C. Silvestrini, M. Mathieu, F. Cutruzzolà, D. Bourgeois, V. Fülöp, J. Hajdu, M. Brunori, M. Tegoni, C. Cambillau, Structure 5 (1997) 1157-1171

[20] J.W.A. Allen, M.R. Cheesman, C.W. Higham, S.J. Ferguson, N.J. Watmough, Biochem. Biophys. Res. Commun. 279 (2000) 674-677

[21] T. Sjogren, J. Hajdu, J. Biol. Chem. 276 (2001) 2945029455

[22] G.W. Pettigrew, A. Echalier, S.R. Pauleta, J. Inorg. Biochem. 100 (2006) 551-567

[23] R. Gilmour, C.F. Goodhew, G.W. Pettigrew, S. Prazeres, J.J.G. Moura, I. Moura, Biochem. J. 300 (1994) 907-914

[24] T. Alves, S. Besson, L.C. Duarte, G.W. Pettigrew, F.M. Girio, B. Devreese, I. Vandenberghe, J. Van Beeumen, G. Fauque, I. Moura, Biochim. Biophys. Acta 1434 (1999) 248-259

[25] S.R. Pauleta, F. Guerlesquin, C.F. Goodhew, B. Devreese, J. Van Beeumen, A.S. Pereira, I. Moura, G.W. Pettigrew, Biochemistry 43 (2004) 11214-11225

[26] A. Echalier, C.F. Goodhew, G.W. Pettigrew, V. Fulop, Structure 14 (2006) 107-117

[27] A. Echalier, T. Brittain, J. Wright, S. Boycheva, G.B. Mortuza, V. Fulop, N.J. Watmough, Biochemistry 47 (2008) 1947-1956

[28] J.L. Boer, B.S. Mulrooney, R.P. Hausinger, Arch. Biochem. Biophys. (2013) http://dx.doi.org/10.1016/j. abb.2013.09.002

[29] J.J.G. Moura, A.L. Macedo, P.N. Palma, Methods Enzymol. 243 (1994) 165-188

[30] C.D. Brondino, M.J. Romao, I. Moura, J.J.G. Moura, Curr. Opin. Chem. Biol. 10 (2006) 109-114

[31] S. Najmudin, P.J. González, J. Trincão, C. Coelho, A. Mukhopadhyay, N.M. Cerqueira, C.C. Romão, I. Moura, J.J.G. Moura, C.D. Brondino, M.J. Romão, J. Biol. Inorg. Chem. 13 (2008) 737-753

[32] N.M. Cerqueira, P.J. Gonzalez, C.D. Brondino, M.J. Romão, C.C. Romão, I. Moura, J.J.G. Moura, J. Comput. Chem. 30 (2009) 2466-2484

[33] C.S. Mota, M. G. Rivas, C.D. Brondino, I. Moura, J.J.G. Moura, P. J. González, N.M. Cerqueira, J. Biol. Inorg. Chem. 16 (2011) 1255-1268

[34] N.M. Cerqueira, P.A. Fernandes, P.J. Gonzalez, J.J.G. Moura, M.J. Ramos, Inorg. Chem. 52 (2013) 10766-10772

[35] S.P. Albracht, E.G. Graf, R.K. Thauer, FEBS Lett. 140 (1982) 311-313

[36] J.J.G. Moura, I. Moura, B.H. Huynh, H.J. Kruger, M. Teixeira, R.C. DuVarney, D.V. DerVartanian, A.V. Xavier, H.D. Peck Jr., J. LeGall, Biochem. Biophys. Res. Commun. 108 (1982) 1388-1393

[37] V.M. Fernandez, E.C. Hatchikian, R. Camack Biochim. Biophys. Acta 832 (1985) 69-79 
[38] M. Teixeira, I. Moura, A.V. Xavier, B.H. Huynh, D.V. DerVartanian, H.D. Peck Jr., J. LeGall, J.J.G. Moura, J. Biol. Chem. 260 (1985) 8942-8950

[39] V.M. Fernandez, E.C. Hatchikian, D.S. Patil, R. Camack, Biochim. Biophys. Acta 883 (1986) 145-154

[40] M. Teixeira, I. Moura, A.V. Xavier, J.J.G. Moura, J. LeGall, D.V. DerVartanian, H.D. Peck Jr., B.H. Huynh, J. Biol. Chem. 264 (1989) 16435-16450

[41] A. Volbeda, M.H. Charon, C. Piras, E.C. Hatchikian, M. Frey, J.C. Fontecilla-Camps, Nature 373 (1995) 580-587

[42] E. Garcin, X. Vernede, E.C. Hatchikian, A. Volbeda, M. Frey, J.C. Fontecilla-Camps, Structure 7 (1999) 557-566

[43] M. Carepo, D.L. Tierney, C.D. Brondino, T.C. Yang, A. Pamplona, J. Telser, I. Moura, J.J.G. Moura, B.M. Hoffman J. Am. Chem. Soc. 124 (2002) 281-286

[44] A. Volbeda, L. Martin, C. Cavazza, M. Matho, B.W. Faber, W. Roseboom, S.P. Albracht, E. Garcin, M. Rousset, J.C. Fontecilla-Camps, J. Biol. Inorg. Chem. 10 (2005) 239-249

[45] A.L. De Lacey, V.M. Fernandez, M. Rousset, R. Cammack, Chem. Rev. 107 (2007) 4304-4330

[46] J.C. Fontecilla-Camps, A. Volbeda, C. Cavazza, Y. Nicolet, Chem. Rev. 107 (2007) 4273-4303

[47] P.M. Vignais, B. Billoud, Chem. Rev. 107 (2007) 4206-4272

[48] M.E. Murphy, S. Turley, E.T. Adman, J. Biol. Chem. 272 (1997) 28455-28460

[49] F.E. Dodd, J. Van Beeumen, R.R. Eady, S.S. Hasnain, J. Mol. Biol. 282 (1998) 369-382

[50] I.S. MacPherson, M.E. Murphy, Cell Mol. Life Sci. 64 (2007) 2887-2899

[51] C. Ascenso, F. Rusnak, I. Cabrito, M.J. Lima, S. Naylor, I. Moura, J.J.G. Moura, J. Biol. Inorg. Chem. 5 (2000) 720-729

[52] T. Jovanovic, C. Ascenso, K.R. Hazlett, R. Sikkink, C. Krebs, R. Litwiller, L.M. Benson, I. Moura, J.J.G. Moura, J.D. Radolf, B.H. Huynh, S. Naylor, F. Rusnak, J. Biol. Chem. 275 (2000) 28439-28448

[53] A.P. Yeh, Y. Hu, F.E. Jenney Jr., M.W. Adams, D.C. Rees, Biochemistry 39 (2000) 2499-2508

[54] M. Lombard, C. Houee-Levin, D. Touati, M. Fontecave, V. Niviere, Biochemistry 40 (2001) 5032-5040

[55] M.W. Adams, F.E. Jenney Jr., M.D. Clay, M.K. Johnson, J. Biol. Inorg. Chem. 7 (2002) 647-645
[56] F. Rusnak, C. Ascenso, I. Moura, J.J.G. Moura, Methods Enzymol. 349 (2002) 243-258

[57] M.D. Clay, F.E. Jenney Jr., P.L. Hagedoorn, G.N. George, M.W. Adams, M.K. Johnson, J. Am. Chem. Soc. 124 (2002) 788-805

[58] V. Adam, A. Royant, V. Niviere, F.P. Molina-Heredia, D. Bourgeois, Structure 12 (2004) 1729-1740

[59] V. Niviere, M. Asso, C.O. Weill, M. Lombard, B. Guigliarelli, V. Favaudon, C. Houee-Levin, Biochemistry 43 (2004) 808-818

[60] V.W. Huang, J.P. Emerson, D.M. Kurtz Jr., Biochemistry 46 (2007) 11342-11351

[61] J.V. Rodrigues, B.L. Victor, H. Huber, L.M. Saraiva, C.M. Soares, D.E. Cabelli, M. Teixeira, J. Biol. Inorg. Chem. 13 (2008) 219-228

[62] V.E. Kagan, V.A. Tyurin, J.Jiang, Y.Y. Tyurina, V.B. Ritov, A.A. Amoscato, A.N. Osipov, N.A. Belikova, A.A. Kapralov, V. Kini, I.I. Vlasova, Q. Zhao, M. Zou, P. Di, D.A. Svistunenko, I.V. Kurnikov, G.G. Borisenko, Nat. Chem. Biol. 1 (2005) 223-232

[63] N.A. Belikova, Y.A. Vladimirov, A.N. Osipov, A.A. Kapralov, V.A. Tyurin, M.V. Potapovich, L.V. Basova, J. Peterson, I.V. Kurnikov, V.E. Kagan, Biochemistry 45 (2006) 4998-5009

[64] A.A. Kapralov, I.V. Kurnikov, I.I. Vlasova, N.A. Belikova, V.A. Tyurin, L.V. Basova, Q. Zhao, Y.Y. Tyurina, J.F. Jiang, H. Bayir, Y.A. Vladimirov, V.E. Kagan, Biochemistry 46 (2007) 14232-14239

[65] J.A. Farrar, A.J. Thomson, M.R. Cheesman, D.M. Dooley, W.G. Zumft, FEBS Lett. 294 (1991) 11

[66] K. Brown, M. Tegoni, M. Prudêncio, A.S. Pereira, S. Besson, J.J. Moura, I. Moura, C. Cambillau, Nat. Struct. Biol. 7 (2000) 7

[67] K. Brown, K. Djinovic-Carugo, T. Haltia, I. Cabrito, M. Saraste, J.J. Moura, I. Moura, M. Tegoni, C. Cambillau, J. Biol. Chem. 275 (2000) 41133

[68] A. Pomowski, W.G. Zumft, P.M. Kroneck, O. Einsle, Nature 477 (2011) 234

[69] E.M. Johnston, S. Dell'Acqua, S. Ramos, S.R. Pauleta, I. Moura, E.I. Solomon, J. Am. Chem. Soc. (2014) doi 10.1021/ja411500p.

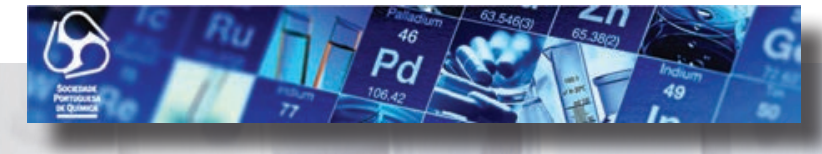

Torne-se Sócio da Sociedade Portuguesa de Química e beneficie de:

- Pertencer a uma comunidade científica dinâmica;

- Receber o boletim "QUÍMICA";

- Descontos nos Encontros promovidos pela SPQ;

- Descontos nas publicações da SPQ;

- Protocolos assinados entre a SPQ e outras entidades;

- Participar na promoção da Química;

- Apoiar uma Sociedade Científica.

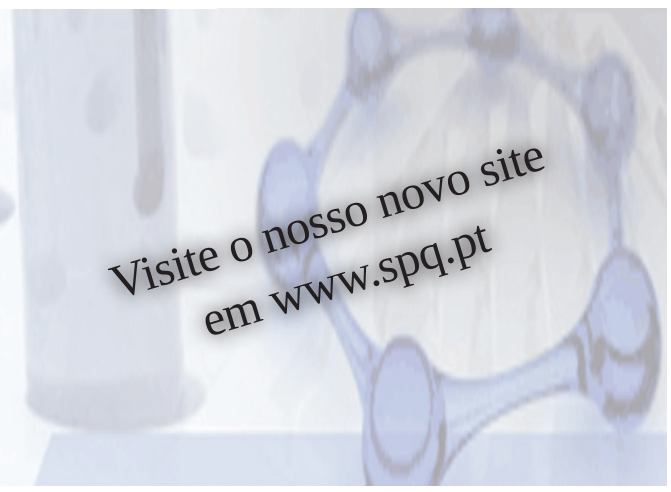




\section{PrimeIRA MOLÉCULA A REAGIR VISTA AO MICROSCÓPIO}

A observação da transformação química de uma molécula individualizada à medida que sofre uma reacção há muito que é um desafio em termos de imagem molecular. Finalmente este sonho químico de podermos ver as moléculas a reagir tornou-se realidade graças a um grupo de quími-
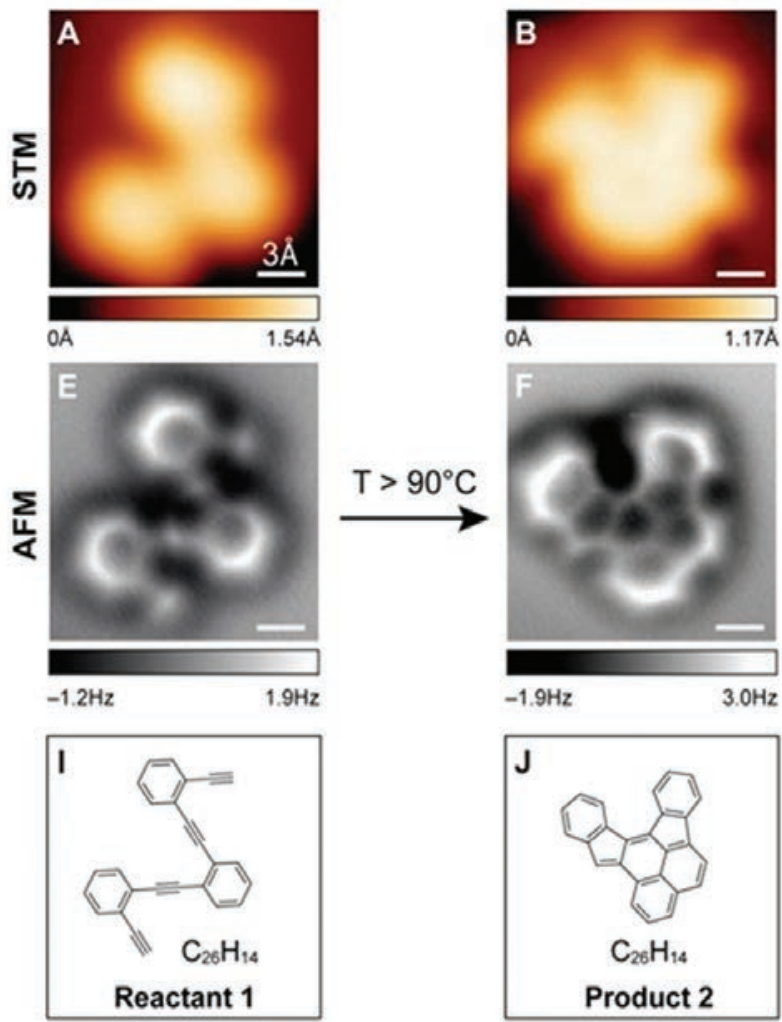

As imagens de microscopia de força atómica (AFM) modo não-contacto de uma molécula, antes e depois da reacção (centro), revelam um muito maior grau de resolução que as imagens obtidas por microscopia de efeito de túnel (STM). É notável o grau de semelhança com a representação que se faz das moléculas há mais de um século (parte inferior). cos e físicos da Universidade da Califórnia em Berkeley, do Lawrence Berkeley National Laboratory e do Centro Internacional de Física de Donostia e da Universidade do País Basco, que recorreu à microscopia de força atómica (AFM) modo não-contacto. Os investigadores obtiveram as primeiras fotos de alta resolução que mostram os átomos de uma molécula da família dos [oligo-(fenileno-1,2-etinilenos)] e as ligações covalentes entre eles. Conseguiram igualmente obter as imagens dos produtos formados por degradação térmica desta molécula. Assinale-se que até ao momento só tinha sido possível inferir este tipo de informação a partir de dados de análise espectroscópica.

A possibilidade de visualizar as reacções químicas por esta técnica poderá não só ser útil aos estudantes de Química como também poderá indicar aos químicos qual o ajuste fino necessário para obter das suas reacções os produtos desejados.

A equipa liderada pelos professores Felix Fischer e Michael Crommie, de Berkeley, obteve estas imagens com o objectivo inicial de construir novas nanoestruturas de grafeno, uma área de pesquisa das ciências de materiais com grande impacto na actualidade pelas possíveis aplicações em futuras gerações de computadores. O uso deste tipo de imagem molecular, todavia, poderá ser ainda alargado a outras áreas como, por exemplo, a catálise heterogénea.

(adaptado de http://newscenter.berkeley.edu/2013/05/30/ scientists-capture-first-images-of-molecules-beforeand-after-reaction/ e de http://www.sciencemag.org/ content/340/6139/1434.abstract)

João Paulo André

(jandre@quimica.uminho.pt)

\section{NoVOS SAIS DESAFIAM FUNDAMENTOS DA QUÍMICA}

Uma equipa de investigadores da State University of New York, EUA, encontrou estequiometrias inesperadas para o cloreto de sódio, mas correspondendo a formas estáveis deste composto. A equipa desenvolveu um código computacional que prevê estruturas cristalinas em condições de pressão e temperatura específicas a partir de uma determinada composição química. Ao usá-lo, a equipa descobriu que podem ser obtidas novas estequiometrias para o cloreto de sódio a pressões elevadas. Compostos tais como $\mathrm{NaCl}_{3}$, $\mathrm{Na}_{2} \mathrm{Cl}, \mathrm{Na}_{3} \mathrm{Cl}_{2}, \mathrm{Na}_{3} \mathrm{Cl}$ e $\mathrm{NaCl}_{7}$, com ligações químicas e propriedades electrónicas pouco comuns, são teoricamente estáveis até $250 \mathrm{GPa}$. No entanto, para estas pressões, o NaCl também é estável. Os investigadores descobriram igualmente que para a obtenção das novas estruturas é necessário uma temperatura elevada e um excesso de Na ou de Cl. Para testar esta previsão, obtiveram experimentalmente duas formas cristalinas de $\mathrm{NaCl}_{3}$, uma acima de 18 GPa e outra acima de $54 \mathrm{GPa}$, na presença de um excesso de $\mathrm{Cl}$. O aquecimento na presença de um excesso de $\mathrm{Na}$ produziu $\mathrm{Na}_{3} \mathrm{Cl}$, estável acima de $20 \mathrm{GPa}$.

(adaptado de http://www.rsc.org/chemistryworld/2013/12/ new-sodium-chlorides-assault-chemical-rules; http:// www.sciencedaily.com/releases/2013/12/131219142138. htm e de W. Zhang et al., Science, 2013, DOI: 10.1126/ science.1244989)

Paulo Mendes (pjgm@uevora.pt) 